\title{
Microbial community profiles grown on 1020 carbon steel surfaces in seawater- isolated microcosm
}

\author{
Luciano Procópio(i)
}

\begin{abstract}
Corrosion of metallic alloys is a concern worldwide, with impacts affecting different production sectors and consequent economic losses in the order of billions of dollars annually. Biocorrosion is a form of corrosion where the participation of microorganisms can induce, accelerate, or inhibit corrosive processes. In this study, it was evaluated that the changes in profile communities, by the sequencing of the 165 ribosomal gene, grown over steel coupons in a microcosm with no additional oxygen supplementation for 120 days. Analysis of abundance and diversity indices indicates marked changes in microbial structures throughout the 120-day period. Homology results of OTUs generated by Illumina sequencing indicated Proteobacteria phylum as the dominant group, comprising about $85.3 \%$ of the total OTUs, followed by Firmicutes and Bacteriodetes, both with $7.35 \%$. Analyses at lower taxonomic levels suggested the presence of representatives described as corroders, such as Citreicella thiooxidans, Thalassospira sp., and Limnobacter thiooxidans. In conclusion, the results suggest that no additional oxygen supplementation profoundly altered the core of microbial communities, with a predominance of facultative anaerobic species.
\end{abstract}

Keywords: Microbially influenced corrosion, Seawater, Steel corrosion, Metagenome, Microcosm

\section{Introduction}

Corrosion of metals is a complex process that involves abiotic factors, such as temperature, physical and chemical stresses, and biotic factors through the direct and indirect action of microorganisms. Although in the scientific literature, the action of eukaryotic microorganisms such as fungi, yeast, and algae are described as corroders, the activity of bacteria and archaea constitutes the major part of the microbially influenced corrosion (MIC) (Lugauskas et al. 2009; Li et al. 2018). Nowadays, the metal deterioration through corrosion is a global concern, impacting numerous economic sectors, in particular, offshore structures, as pipeline, navies, and harbors, and studies of the economic impacts of corrosion demonstrate that values can reach US\$2.5 trillion per year, which represents $3 \%$ of gross domestic product (GDP) (Koch et al. 2016). Expensive protective actions against corrosion processes are currently available, such

Correspondence: Iucianoprocopio@caxias.ufrj.br

Industrial Microbiology and Bioremediation Department, Federal University of Rio de Janeiro (UFRJ), Caxias - Rio de Janeiro, Brazil as organic and inorganic coatings, plastics covers and paints, and cathodic protection, which consists in creating a galvanic cell, and thus, acting with a "sacrifice metal," maintenance and inspection costs are also considerable (Baeckmann 1997; Price and Figueira 2017). In addition to these activities described, protective actions, such as inspection, maintenance, and training of specialized technicians, may add an estimated $\$ 121$ billion to the total cost, thus corroborating the high economic impacts of corrosion on industries (Koch et al. 2002; Thompson et al. 2007).

The presence of microorganisms over metal surfaces and their consequent attack occurs through bacterial biofilm structures. Biofilms are a complex formed by bacteria and extracellular compounds, such as proteins, DNA, polysaccharides, and metabolites (Procópio 2019). Biofilm formation is a process widely found on different inanimate or organic surfaces, under different environmental conditions that influence their presence and persistence. The forces involved in forming these structures may include nutrient deprivation, continuous water flow, 
extreme or unfavorable temperatures, protection against harmful chemical compounds, biocides, and antibiotics (Salta et al. 2013). The formation of the biofilm on the metals allows the generation of an internal microenvironment, which makes it possible to induce/accelerate the metallic corrosion. The process of metal deterioration happens when the surface acts with an anodic site, transferring electrons from the zero-valent metal to a cathodic site, in this case, the bacterial biofilm (Hamilton 2003). This redox reaction would also occur in abiotic corrosion; however, the MIC allows to accelerate the whole process up to $1000 \times$ (Melchers and Jeffrey 2013; Marty et al. 2014). Microorganisms can induce corrosion by altering $\mathrm{pH}$ and oxidation-reduction potential $\left(E_{h}\right)$ in the secretion of corrosive metabolites or even directly acting in oxidation-reduction reactions through extracellular enzymes (Little et al. 2007).

Sulfate-reducing bacteria (SRB) was the first bacterial group to be described as active participants in metal corrosion (Tiller and Booth 1962). Previously, SRB received the most attention in studies on anaerobic MIC, mainly for $\mathrm{H}_{2} \mathrm{~S}$ production, which exerts a strong corrosive action (Kato 2016). Currently, several other bacterial groups with distinct metabolisms are known to be involved in corrosion processes, either directly or indirectly. Sulfate-oxidizing bacteria (SOB), iron-reducing bacteria (IRB), acid-producing bacteria (APB), thiosulfate-reducing bacteria (TRB), Fe-oxidizing bacteria $(\mathrm{FeOB})$, and sulfate-reducing archaea (SRA) are commonly described in studies of metal corrosion (Beech and Sunner 2004; Videla and Herrera 2005; Li et al. 2017). Progressively, surveys have shown the participation of heterotrophic aerobic microorganisms as having a preponderant role in corrosion, either as in maintaining corrosive biofilm or participating directly in the metal attack. In a marine environment, the presence of $\mathrm{FeOB}$ lithotrophic bacteria has been related to iron oxidation under neutral $\mathrm{pH}$ conditions (Emerson 2018). Another heterotrophic group recently described as involved in corrosion is the APB group. The production of acid metabolites, such as formic acid $(\mathrm{HCOOH})$, acetic acid $\left(\mathrm{CH}_{3} \mathrm{COOH}\right)$, and lactic acid $(\mathrm{CH} 3 \mathrm{CHCOOH})$, allows metal deterioration by shifting the inner pH of biofilms (Ray et al. 2010; Xu et al. 2016). These new findings on different microbial metabolic groups involved in corrosion show that corrosion is a multifactorial complex process where the participation of microorganisms is not limited to a single group or environmental condition.

This complex system found in the inner corrosive biofilms, which involves various microorganisms, extracellular material, and different chemical conditions, is a challenge for biocorrosion studies, especially under in situ conditions. Nonetheless, establishing the direct relationship between biofilm and metal corrosion under laboratory conditions, employing a single bacterial species, may not reflect reality, since there is usually the participation of a complex microbial community. An alternative is the use of microcosm systems, where there is an effort to design a closed system in the laboratory that simulates the maximum conditions present in the environment (Angell et al. 1997; Mumford et al. 2016; Moura et al. 2018). One methodology that has been widely employed for the study of biocorrosion under meso- and microcosm conditions, and also in situ environmental conditions, is the description of the microbial community through sequencing of the $16 \mathrm{~S}$ ribosomal gene.

The microbial amplicons of the 16S rRNA genes, also called metagenome, enable the description of the taxonomic profile of complex systems of microbial populations present in different samples from natural environmental sites (Rondon et al. 2000; Tyson et al. 2004). Despite the limitations of metagenome techniques, such as metagenomic methods only describe the taxonomic profile of the biofilm but do not establish a physiological relationship of microorganisms and the corrosion process, in addition to metagenomic sequencing identifying species levels, and many of the characteristics metabolic are found at strain levels, numerous studies employing high-throughput techniques shed light on the participation of microorganisms involved in corrosion (Dang et al. 2011; Park et al. 2011; Rajala et al. 2015; Ramírez et al. 2016; Vigneron et al. 2016; Bonifay et al. 2017; Moura et al. 2018). In this study, the analysis of isolated environmental factors can contribute to the understanding of changes in the microbial community, and based on this, we use metagenomics to evaluate how the structure microbial community changes over time in a system where there is no oxygen entry into the microcosm.

\section{Material and methods}

\section{Microcosms design}

For the microbiological succession analysis on the coupons, a microcosm was designed, which consisted of a glass tank with an approximate capacity of $8 \mathrm{l}$. The tank was previously autoclaved, and then seawater was added until it was filled. The seawater used in this experiment was collected near the Brazilian Navy Ship Maintenance Area, located in Cobras Island, Rio de Janeiro, RJ. The microcosm was maintained at the Microbial Corrosion Laboratory, located at Estacio University in Rio de Janeiro. The conditions maintained were water temperature around $23{ }^{\circ} \mathrm{C}$, which corresponds to the seawater temperature at the collection site, a period of $12 \mathrm{~h}$ of light daily, and after the coupons had been accommodated, the microcosm was sealed to prevent additional entry atmospheric air.

\section{Coupon preparation}

AISI-1020 steel coupons were used with about $1 \mathrm{~cm}^{2}$ of the total surface. The chemical composition of the coupons consisted of $\mathrm{C}=16 \%, \mathrm{Mn}=0.63 \%, \mathrm{P}=1.2 \%, \mathrm{~S}=$ $3.1 \%, \mathrm{Si}=1.2 \%, \mathrm{Cu}=1 \%, \mathrm{Cr}=3 \%$, and $\mathrm{Ni}=1 \%$. The 
coupons were sanded using metal sandpaper, with progressive reduction of grain size, for complete cleaning of the cover material. Then, they were incubated with absolute decreasing ethanol, washed with acetone to remove organic matter, and oven-dried at $70{ }^{\circ} \mathrm{C}$ for $30 \mathrm{~min}$. Subsequently, the coupons were autoclaved, cooled, identified, and wrapped by nylon strings into the water tank, which was immediately closed.

\section{Community analysis}

All coupons were incubated in the microcosm for a total of 120 days. Communities grown on coupon surfaces were analyzed after $5,30,60$, and 120 days of exposure to seawater. At each sampling time, the coupons were removed and the surface-covered biofilm was scraped off and immediately sent for extraction of the DNA and sequencing the 16S bacterial DNA gene (Gohl et al. 2016). Each sample obtained was packed in a sterile $1.5-\mathrm{mL}$ tube and sent to Neoprospecta Microbiome Technologies (Florianópolis-SC, Brazil). Sample preparation and sequencing were performed by Neoprospecta Microbiome Technologies. It consisted of the $16 \mathrm{~S}$ rRNA V3/V4 region, which was amplified using 341F (5'-CCTACGGGRSGCAGCAG-3') and 806R (5'-GGACTACHVGGGTWTCTAAT-3') primers, which were required for sequencing. Amplification was performed in 35 cycles at $50{ }^{\circ} \mathrm{C}$ annealing temperature, which was tripled for each sample. Sequencing was performed by Illumina MiSeq using V2 kits with a 300-nt run (Gohl et al. 2016).

The bioinformatics analyses were performed by Neoprospecta Microbiome (Florianopolis, SC, Brazil). The primer and adapter sequences were trimmed from the reads and only sequences, with 275 nt or more, were used in downstream analysis. Then, all reads with one or more indeterminate " $\mathrm{N}$ " bases and truncated sequences with two or more consecutive bases with quality scores below Q20 were eliminated. OTU picking was performed using BLASTN 2.2.28 against the GreenGenes 13.8 database. In order to attribute taxonomy, only sequences with $99 \%$ of identity hits in an alignment covered over $99 \%$ were considered.

\section{Data analysis}

Diversity indices were calculated using the Shannon and Simpson measures, while Chaol was used to evaluate non-parametric richness estimators using the software Past3. Rarefaction curves and dissimilarity index, based on the four conditions evaluated, were measured using the iNEXt and the Vegan packages, available in the R Studio software (Hsieh et al. 2016). Stacked bar charts and bubble plots were built using the Ggplot2 and Vegan packages, available for R Studio software (Wickham 2009). Changes in the structural profile of the temporal conditions were analyzed for differences between OTU abundances by calculating the Bray-Cutis index. The graphs used to present the principal coordinates analysis (PCoA) and non-metric multidimensional scaling (NMDS) related to diversity measurement data were constructed using the Vegan and Ggbiplot packages, specifically using the metaMDS() and $\operatorname{prcomp}()$ functions.

\section{Results}

\section{Diversity analyses}

The analysis of heterogeneity indices by Shannon and Simpson measures indicated a gradual decline of the values over the experimental period and with a visible drop in the index after 120 days (Fig. 1a, b). The abundance indices analyzed by the Chaol method showed a distinct behavior from the heterogeneity analysis, whereas the results of the samples for 5 and 30 days had similar values and the 60-day condition displayed a high abundance measures. Conversely, 120 days of incubation in the microcosm revealed an abrupt decline in the abundance index (Fig. 1c). The alpha diversity indices for the abundance of Chao1 in all periods were compared between them and presented in Fig. 1d. The results suggest a visible dominance among samples for 5, 30, and 60 days in the alpha diversity indices, with a low and persistent index value in the 120-day condition (Fig. 1d). The results showing the differences between the community structures of the analyzed microcosms can also be seen in the rarefaction curve analysis with the same characteristics as those exhibited in the previous results (Fig. 2).

The microbiome structure exposed in PCA biplot analysis outlined the distinct profile of all samples analyzed. The first component explained $45.96 \%$ overall variance among the four conditions, whereas the second component explained $41.97 \%$ of the total variance and showed a clear separation of all temporal analyses (Fig. 3a). Nonmetric multidimensional scaling (NMDS) based on BrayCurtis distance was performed to compare dissimilarity between the compositions of the microbial communities. The results showed in the NMDS plot confirm a clear separation of the studied communities (Fig. 3b).

\section{Community diversity}

The Illumina sequencing results generated a total of 29 , 074 good quality OTUs, which were distributed among the samples as follows: 10,215 OTUs $(35.1 \%)$ detected at 5 days analysis, 7525 OTUs (25.9\%) at 30 days, 11,317 OTUs (38.9\%) at 90 days, and only 17 OTUs $(0.1 \%)$ after 120 days. Distributions of OTU numbers among taxonomic groups show that the highest values were at 60 days, followed by 5 and 30 days, respectively, whereas OTU numbers in the 120-day sample were persistently below the values of other analyses (Fig. 4). The total OTUs were distributed in 82 different taxonomic groups, with a massive representation of Proteobacteria 
(a)

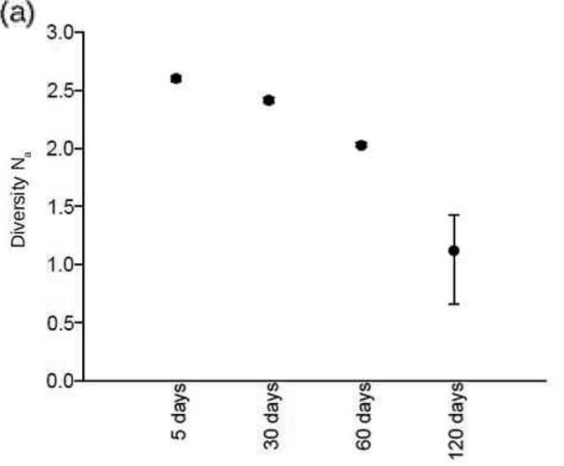

(c)

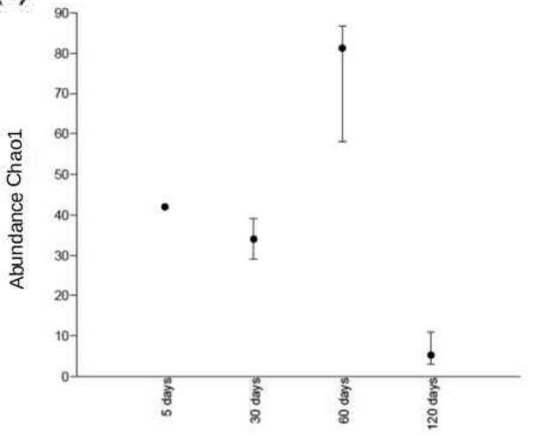

(b)

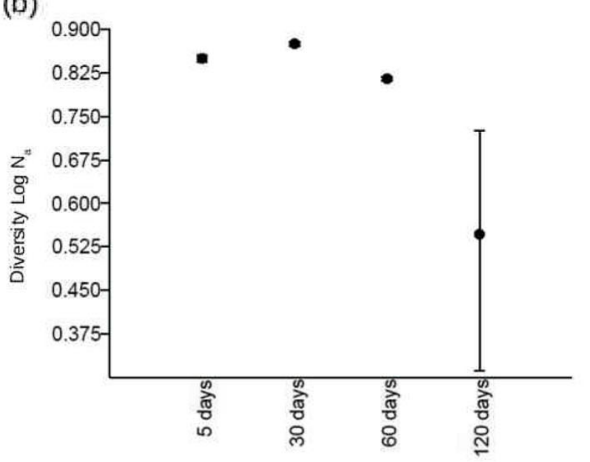

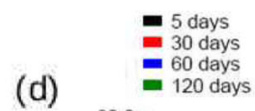

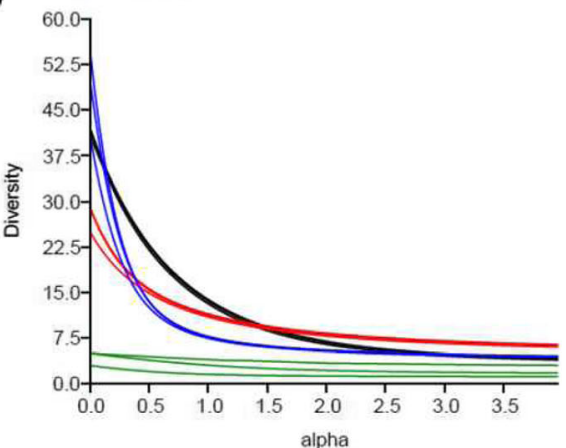

Fig. 1 Diversity and abundance indices of the samples after 5, 30, 60, and 120 days in isolated microcosm. Panels a and $\mathbf{b}$ show the Shannon and Simpson diversity indices. c Abundance measurement index calculated by the Chao 1 method. $\mathbf{d}$ Comparison between diversity indices of samples 5, 30, 60, and 120 days

phylum, with 70 representatives (85.3\%) out of 82 , followed by Bacteriodetes and Firmicutes, both with 6 representatives $(7.35 \%)$ each.
In the first 5-day analysis, the sequencing results identified 41 different taxonomic groups. At the class level, the largest number of representatives was Alphaproteobacteria with 25

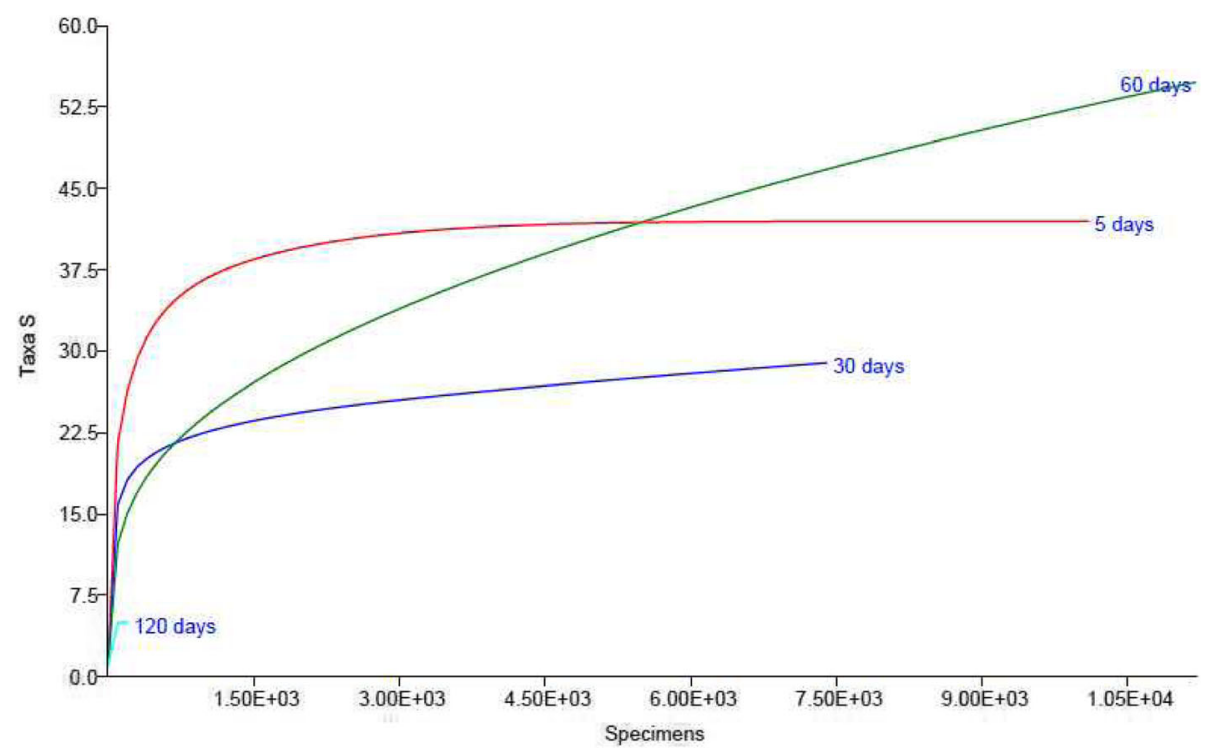

Fig. 2 Rarefaction curve analysis of all samples describing the relationship between OTU numbers ( $x$-axis) and taxonomic diversity ( $y$-axis) 
(a)

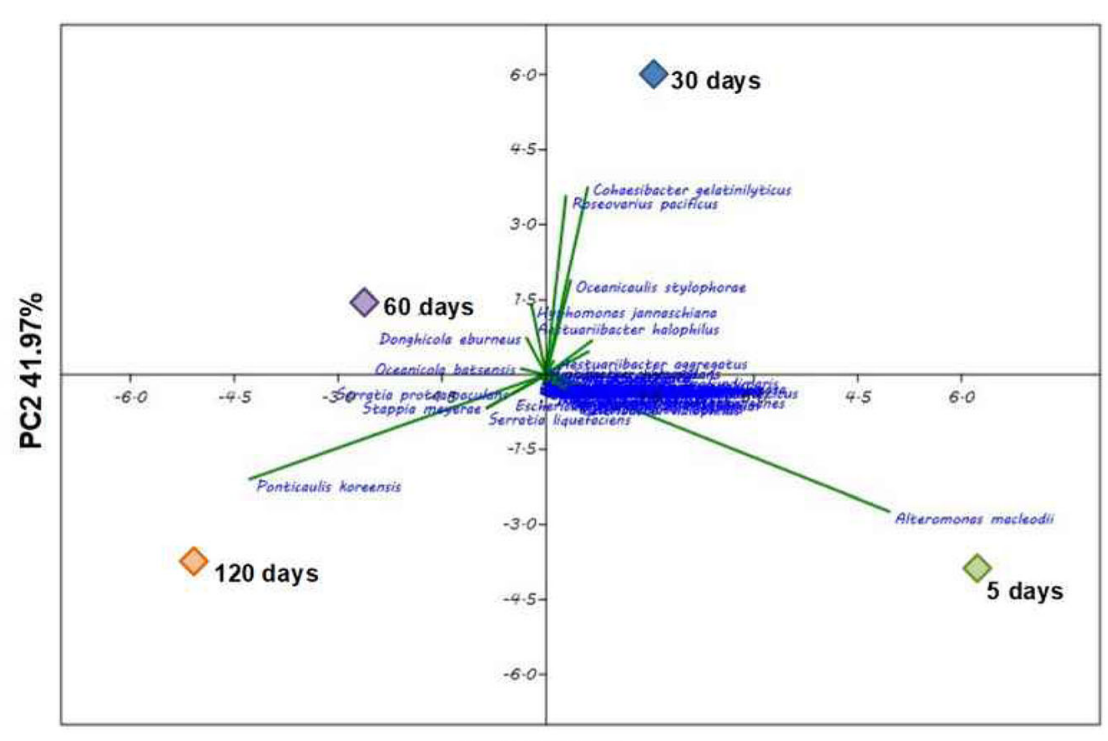

PC1 $45.96 \%$

(b)

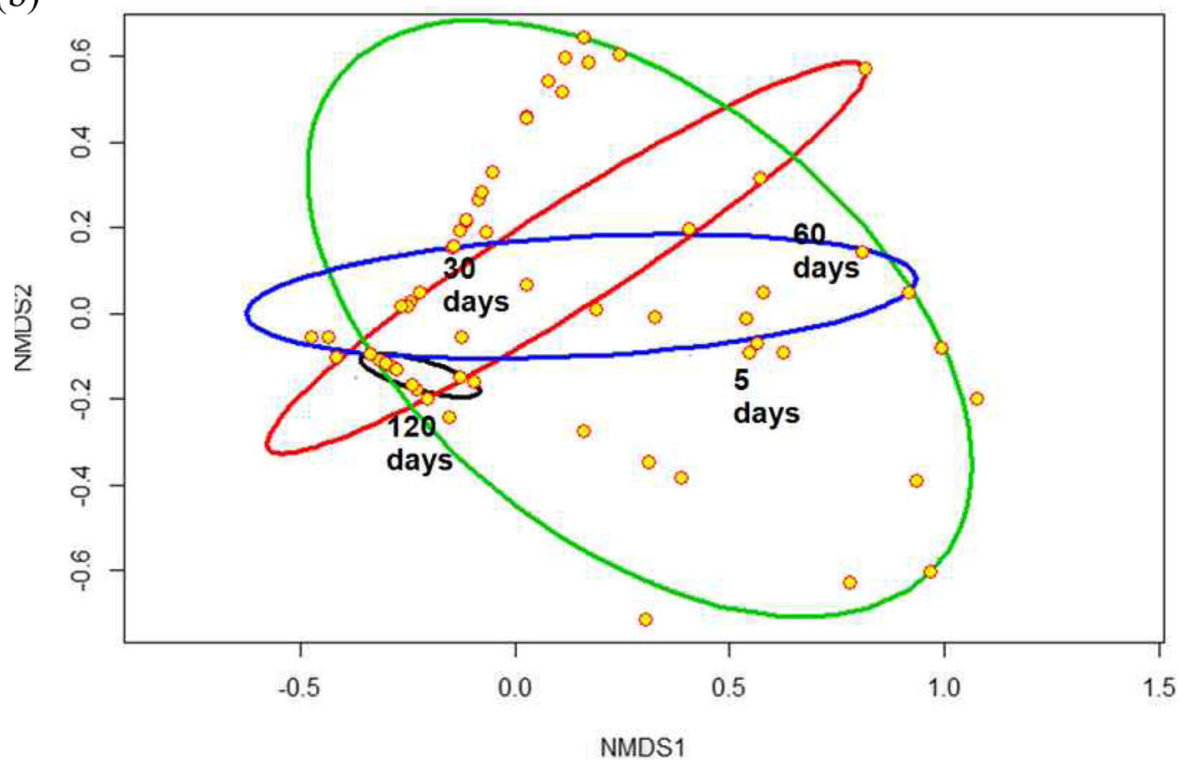

Fig. 3 a Principal component analysis (PCA) calculated using Bray-Curtis measurements. Correlated negative variables are arranged on opposite sides of the chart. The points referring to the indices of each sample are shown in the form of a diamond. Those highlighted in blue are the positions of the taxonomic members in concerning to the axes. b Non-metric multidimensional scale (NMDS) showing differences in microbial communities among the samples of the four analyzes. The distance between the points indicates the degree of difference between the variables. The ellipses indicate the approximation of the analyzed periods

different members, followed by Gammaproteobacteria, and despite the latter showed a larger number of OTUs, 5433 against 4678 of the Alphaproteobacteria (Fig. 5). Flavobacteria and Bacilli classes were also present with two and one members, respectively (Fig. 5). When data are analyzed at the order taxonomic level, there was a predominance of Alteromonadales, with $45 \%$ of the OTUs belonging to the analysis of 5 days of Gammaproteobacteria, follow by Rhodobacterales with $40 \%$ of the OTUs, belonging to
Alphaproteobacteria class (Fig. 6). The order Rhodobacterales presented 4060 OTUs, distributed among 23 different members, whereas in Alteromonadales, the 4578 OTUs were divided into only six different representatives. Really, Alteromonas macleodii, of the Alteromonadales order, was the taxonomic representative with the highest OTU number, 3572, which alone represented $12.3 \%$ of all identified (Fig. 7). Also belonging to the order Alteromonadales was detected the hydrocarbon-degrading bacterium 


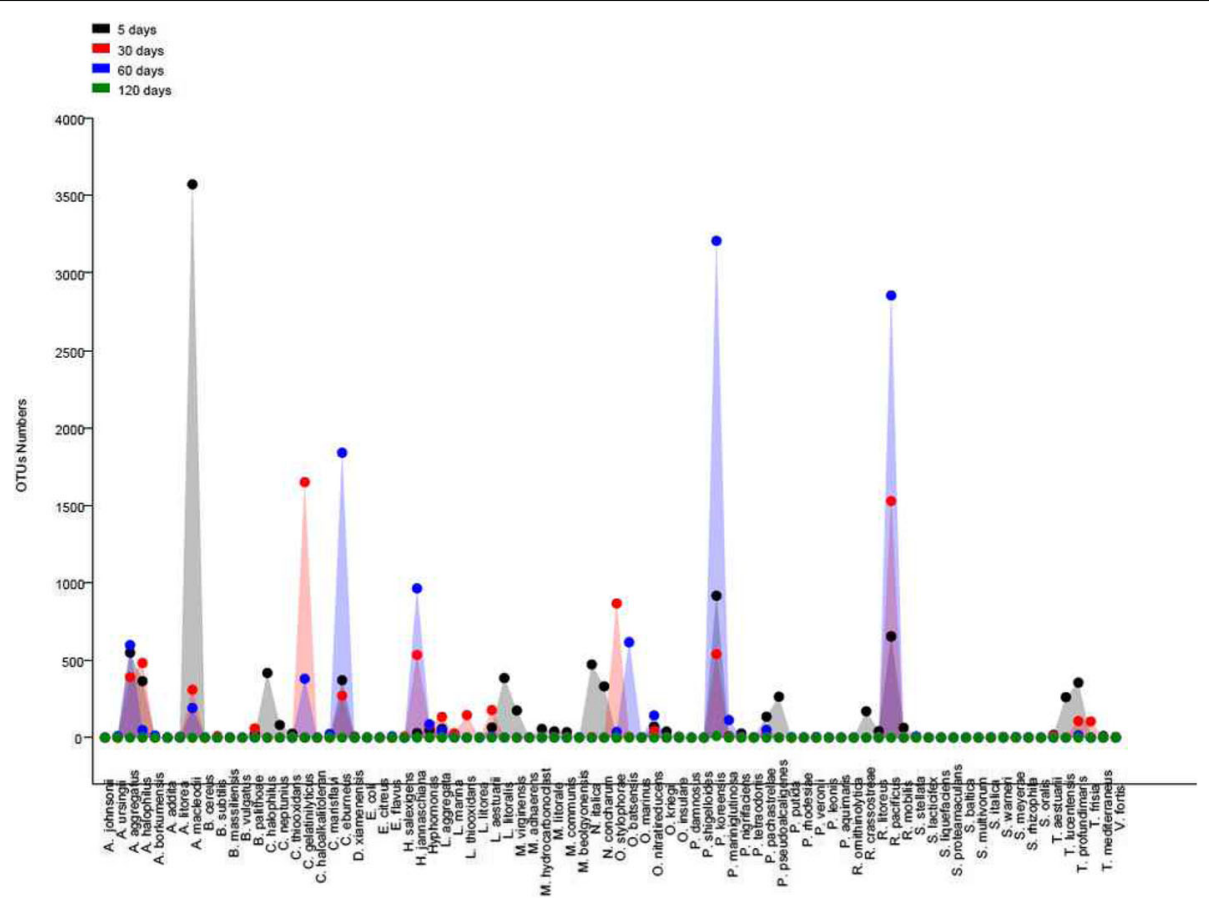

Fig. 4 Relationship between the number of OTUs and the microbial groups of the four temporal analyzes.

Marinobacter hydrocarbonoclasticus (Fig. 7). Among the major representatives of the Rhodobacterales order that were identified are the lithoheterotrophic sulfur-oxidizing Citreicella thiooxidans, the reducing nitrate Oceanicola nitratireducens, and the Roseovarius and Ruegeria genera (Fig. 7). The Rhodospirillales order was represented with only two members, constituting $6 \%$ of the 5 -day OTUs, both of the genus Thalassospira (Fig. 7). Finally, Pseudomonas pseudoalcaligenes $(2.5 \%)$ of the Pseudomonadales order (4\%) and Oceanobacter kriegii of the Oceanospirillales order (4\%), with 40 detected OTUs, were identified after 5 days of experiment (Fig. 7).

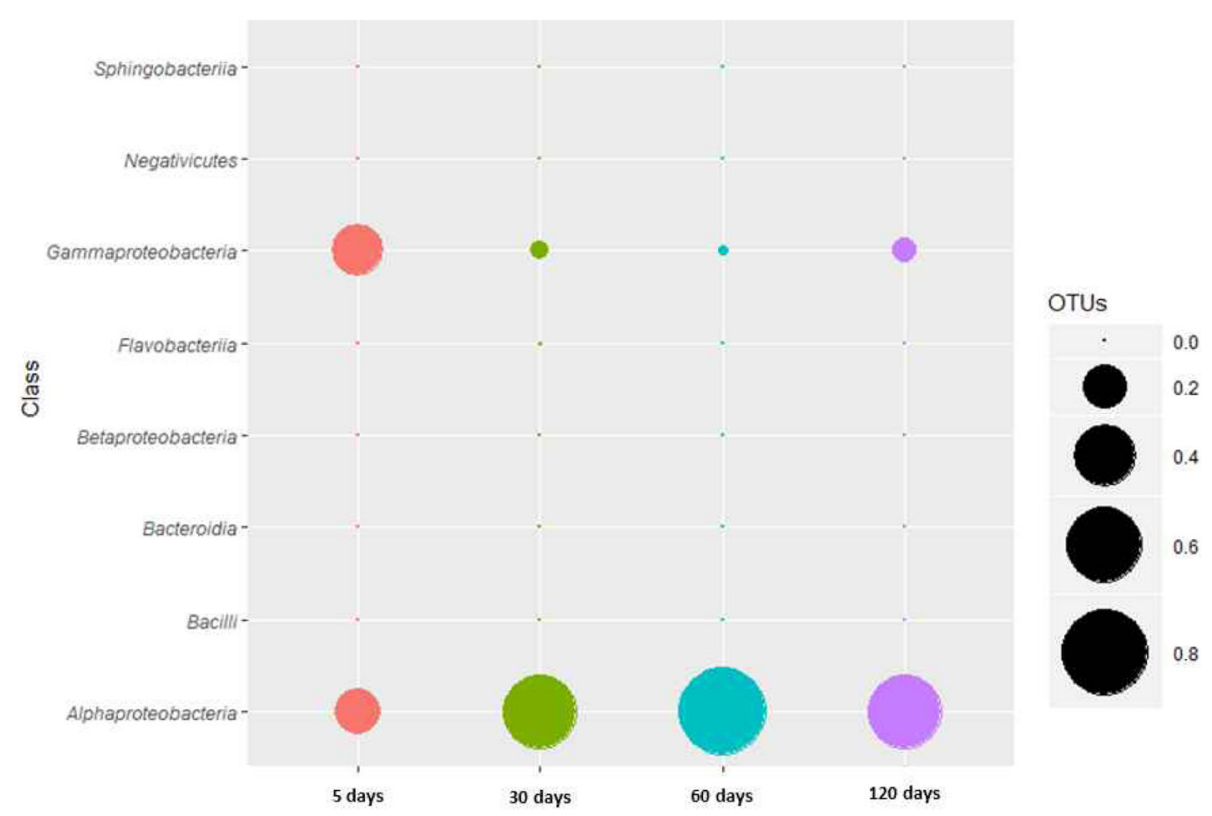

Fig. 5 Bubble plot showing the relative abundance of OTUs among the class-level taxonomy ( $y$-axis) in relation to the temporal analysis ( $x$-axis) 


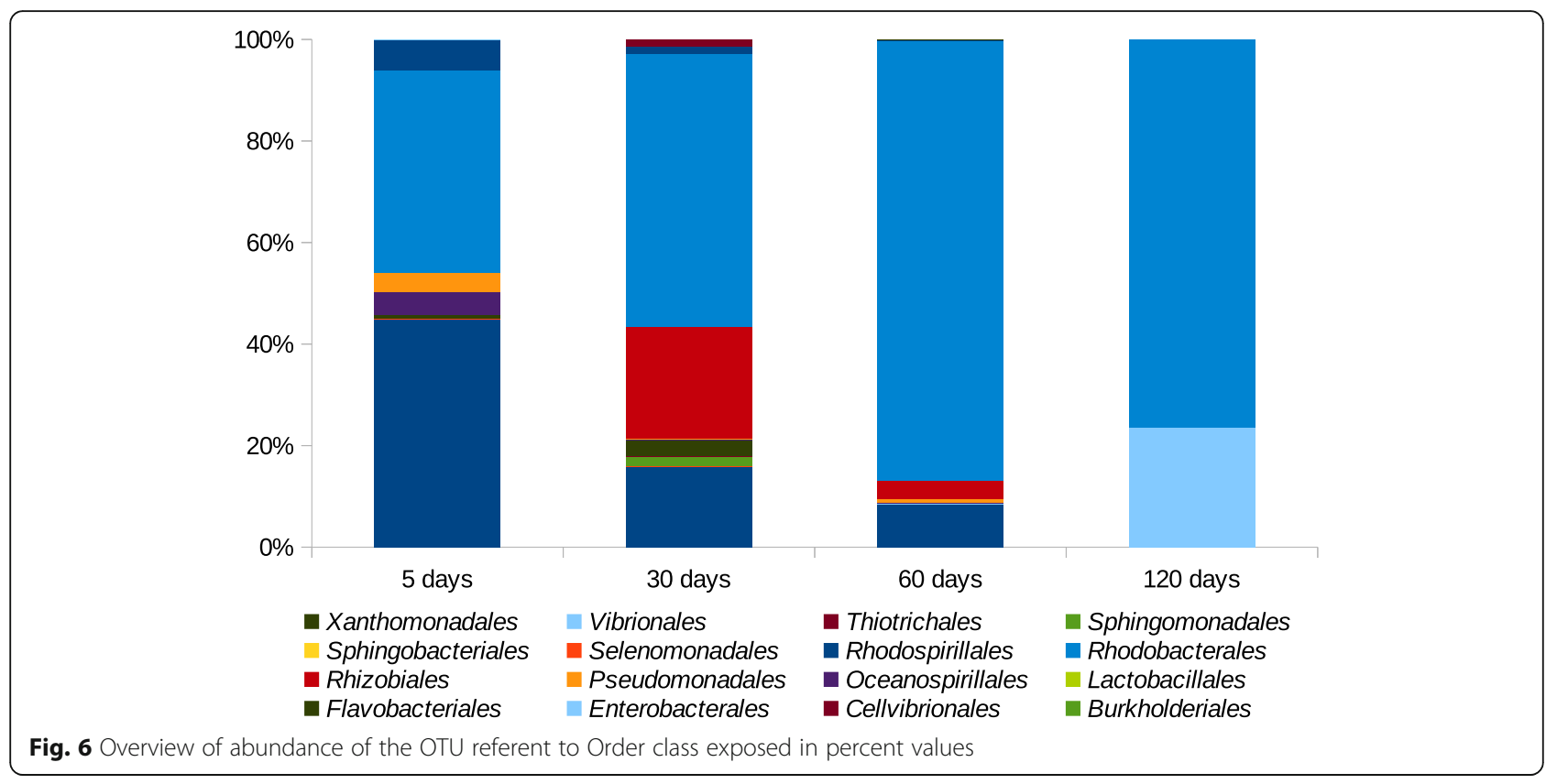

After 30 days of exposure to seawater in the microcosm, there was a noticeable decrease in the number of detected OTUs (7525) and taxonomic groups, with 29 different members identified. The dominant class in this analysis was Alphaproteobacteria, and also with 5807 OTUs distributed among 17 representatives (Fig. 5). The most emblematic order among the Alphaproteobacteria class was Rhodobacterales with 14 different members, which constituted $53.7 \%$ of all OTUs (Fig. 6). The genus Roseovarius was again detected in this analysis, with a considerable number of OTUs (1523) among all genera, which alone represented 20.3\% (Fig. 7). The genera Oceanicaulis (11.5\%), Hyphomonas (8.2\%), Labrenzia (2.1\%), Oceanicola (5.8\%), Ponticaulis (7.1\%), and Thalassospira (1.5\%) were also identified among the Alphaproteobacteria class (Fig. 7). Gammaproteobacteria was the second-largest class in the 30-day analysis, with 1384 OTUs (17.5\%), although only eight different representatives were detected. The main representatives of Gammaproteobacteria were the genera Aestuaribacter and Alteromonas, both belonging to the Alteromonadales order (Fig. 6). Pseudoalteromonas mariniglutinosa and Pseudomonas pachastrellae were detected after 30 days of microcosm incubation, as well as Marinobacterium litorale of the order Oceanospirillales (Figs. 6 and 7). For the first time, the thiosulfate-oxidizing bacteria Limnobacter thiooxidans of the Betaproteobacteria class with 146 OTUs (2\%) was identified (Figs. 6 and 7). In addition, Flavobacteria and Bacilli class members were detected, although with low numbers of representatives and OTUs (Figs. 6 and 7).
The results of Illumina sequencing data analysis after 60 days of experiment showed the highest number of OTUs $(11,317)$, as well as the number of members of taxonomic groups, with 56 different members. Once more, the Alphaproteobacteria class was the most representative, with 10,246 OTUs, constituting 90.7\% alone, divided into 24 different genera. The most significant order was Rhodobacterales, which represented $86.6 \%$ of the OTUs detected in this condition. This elevated number can be exemplified by the representatives Donghicola eburneus (1838 OTUs), Ponticaulis koreensis (3206 OTUs), and Roseovarius pacificus (2855 OTUs), which together constituted $69.8 \%$ of the detected OTUs (Figs. 6 and 7). The genera Hyphomonas (9.2\%), Labrenzia (0.3\%), and Oceanicola (6.7\%) continued to be detected, and Stappia meyerae genus of the Rhodobacterales order was first identified in this condition (Figs. 6 and 7). The analysis of Gammaproteobacteria class analysis, despite presenting OTU numbers well below the other results with only 1051 (9.2\%), allowed identifying 20 different taxonomic groups. The most representative order among Gammaproteobacteria was Alteromonadales (960 OTUs), with nine members identified (8.4\%), including Aestuariibacter, Alteromonas, Marinobacter, Pseudoalteromonas, and Shewanella genera (Figs. 6 and 7). L. thiooxidans of Betaproteobacteria was again detected after 60 days, as well as members of the Flavobacteria and Bacilli classes.

In the last analysis, corresponding to 120 days of incubation in isolated microcosm, there was a sudden drop in diversity and abundance. In this period, only five 


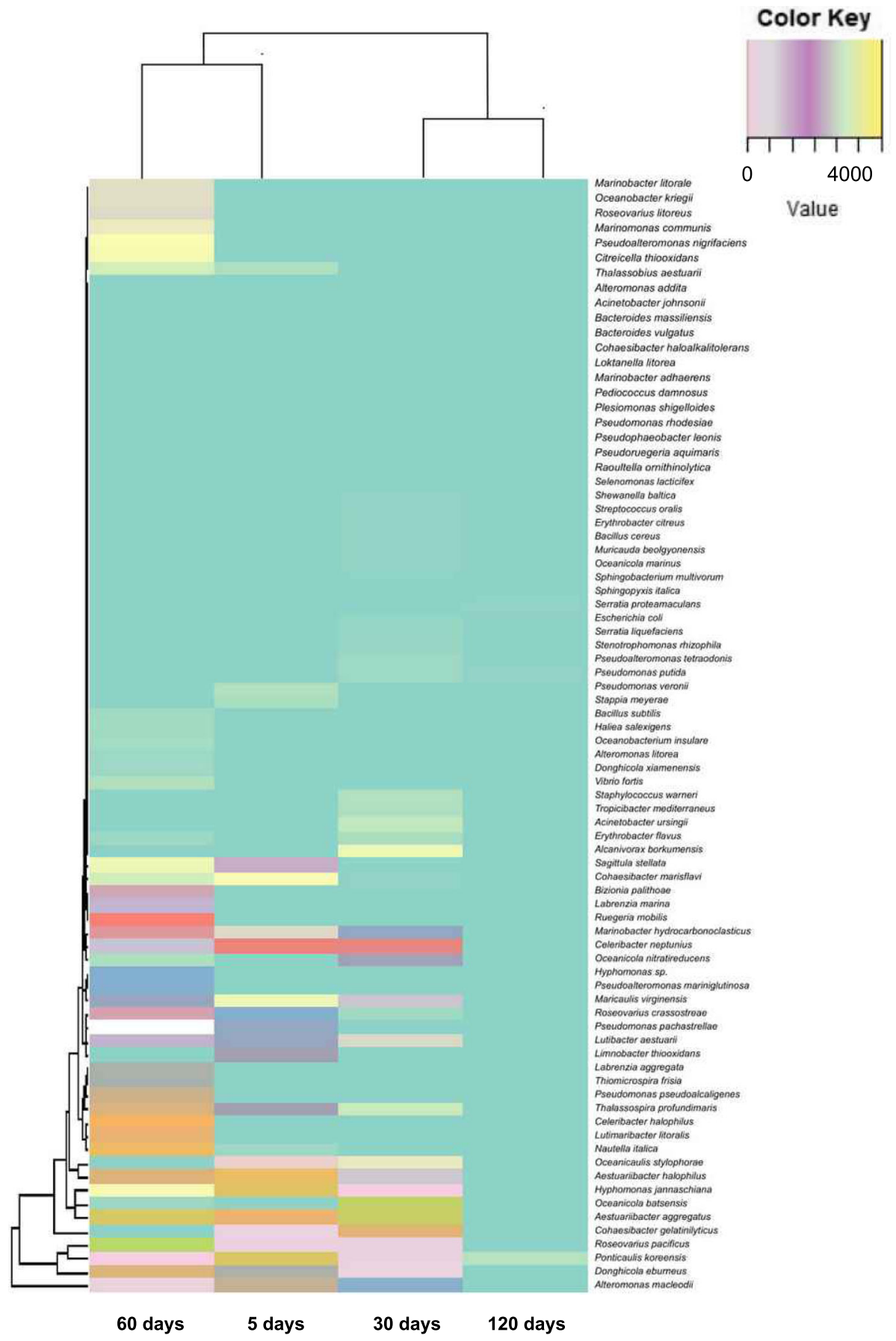

Fig. 7 Heatmap illustrating the bacterial community distributions among the four samples at species levels

different representatives were identified among the 17 OTUs generated. Two genera of the Alphaproteobacteria class, Ponticaulis koreensis and Stappia meyerae, presented higher numbers of OTUs, 11 and 2, respectively. While among the members of Gammaproteobacteria, only the genera Escherichia and Serratia were identified (Figs. 6 and 7).

\section{Discussion}

Several environmental factors related to microbial metabolism influence the acceleration, induction, and inhibition of metal corrosion. Despite the fact, the choice for simulating natural environments, employing microcosm may seem not to correspond to the ideal processes that develop in the real environment and conducting 
experiments under controlled conditions contribute to understanding how each abiotic or biotic factor affects metallic corrosion. Microcosm studies employed in the microbial community in MIC can be challenging. Indeed, there are few studies on MIC studies in microcosm conditions. However, such studies have provided valuable information about the microbial structures involved, directly or indirectly in metal corrosion (Rajala et al. 2015; Ramírez et al. 2016; Li et al. 2017; Moura et al. 2018).

With the advent of 16S DNA gene sequencing techniques from environmental samples, called metagenome, several studies have shown how the corrosive biofilm on metals is constituted under different conditions, either in natural or under micro- and mesocosm conditions, thus allowing a better understanding of the role of microbial groups that are exerting direct corrosion of the attacked metal (McBeth and Emerson 2016; Dang and Lovell 2015; Moura et al. 2018). This study analyzed the microbial succession grown over steel coupons in a microcosm simulating the marine environment. A period of 120 days without additional oxygen supplementation was described by metagenomic methods of the microbial community profiles after 5,30 , 60 , and 120 days. The results about abundance and diversity measurements suggested a fundamental alteration in the biofilm structure throughout the experiment. This trend was confirmed by the results obtained by Illumina sequencing, demonstrating marked changes in the taxonomic profile, with a prevalence of particular representatives with facultative metabolism for aerobiose or anaerobiose.

The predominant phylum in all our analyzes was Proteobacteria. The ubiquity of Proteobacteria is widely described as the main taxonomic group present in MIC, especially in marine environments (Lopez et al. 2006; Li et al. 2017; Salerno et al. 2018; Staniszewska et al. 2019). Alphaproteobacteria was the largest abundant class in our analysis over 120 days. The main representatives of this bacteria group were the genera Ponticaulis, Hyphomonas, Labrenzia, Oceanicaulis and Oceanicola, and Citreicella and members of the order Rhodobacterales. Ponticaulis koreensis was the only bacteria detected throughout the experiment. This bacterium is described as necessarily halophilic and with optional anaerobic metabolism (Kang and Lee 2009). The marine nitrate reducer Oceanicola nitratireducens was present in the first three analyzes, not being detected after 120 days, although it is described as capable of nitrate reduction in anaerobic conditions (Zheng et al. 2010). Another genus of the order Rhodobacterales associated with corrosion was the sulfur-oxidizing bacterium Citreicella thiooxidans, identified in the first 5-day sample. Only the genus Thalassospira of the order Rhodospirillales was identified in samples referring to 5, 30, and 60 days of the experiment. A study on carbon steel corrosive biofilm in pipeline identified the presence of iron-reducing bacteria Thalassospira sp. (Lopez et al. 2006). This genus has been linked to corrosion of carbon steel in marine environments, usually alongside other genera such as Marinobacter, a member of the Gammaproteobacteria class (Chen et al. 2019a and b).

In fact, the Gammaproteobacteria class is constantly related to the corrosion process in metals, and in our surveys, Gammaproteobacteria also occupied a considerable proportion in the bacterial community during the 120 days. Alteromonadales was the most frequent order, especially the Alteromonas, Aestuariibacter, and Pseudoalteromonas genera, always in elevated numbers of OTUs. These genera were previously detected in experiments to influence microbiological succession in carbon steel corrosion (Ramírez et al. 2016; Moura et al. 2018). Also identified was the Shewanella bacteria, which is a member of the Alteromonadales order in the 60-day sample. Some species of this genus are ubiquitous in metal corrosion studies (Miller et al. 2018; Staniszewska et al. 2019; Suma et al. 2019). Another order recognized constantly was Pseudomonadales, which had the Pseudomonas as sole representative. Several studies on metal corrosion in marine environments describe the participation of this bacterium, especially in surveys of oil pipeline-associated microbial community structures or in oil spillcontaminated marine environments (Ramírez et al. 2016; Salerno et al. 2018; Staniszewska et al. 2019). In the last analysis performed after 120 days, E. coli and Serratia sp., both members of the Enterobacterales order, were identified. Both representatives were described in a study on the biodiversity of marine bacteria involved in corrosion (Boudaud et al. 2010). The only member of the Betaproteobacteria class was L. thiooxidans, which is belonging to the order Burkholderiales. Members of this order are described as being able to use hydrogen as the sole source of energy (Stöhr et al. 2001). The presence of $L$. thiooxidans can be suggested due to hydrogen release from metallic surfaces during the corrosion process and studies also suggest that members of this order are capable of accelerating corrosion of carbon steel through iron oxidation (Hedrich et al. 2011; Liu et al. 2012). The results and discussion described above demonstrate the structures of bacterial communities involved in carbon steel corrosion and present the presence of members of different classes of Proteobacteria phylum. A possible explanation would be the initial role of colonization of the metal surface by these members and the consequent maintenance of the biofilm structure, which has important consequences for the development of the biofilm and the maintenance of favorable conditions inside it (Dang et al. 2011; Li et al. 2017; Procópio 2019).

The Firmicutes phylum was described in the first three analyzes of Illumina sequencing, with the predominance 
of the Bacilli class. Representatives of this class were detected sparingly over the period analyzed. Despite the genus Bacillus has been identified only in the 30- and 60 -day samples, it is usually present in studies of carbon steel corrosion, especially in marine environments (Wan et al. 2017; Guo et al. 2019). Similar to the results of Fimicutes, the Bacteroidetes phylum was described in the samples referring to 5, 30, and 60 days of the experiment, having as main representatives the members of the Flavobacteria class. Bacteroidetes are dominant in marine environments and are also widely found in corrosive biofilms (Kirchman 2003; Dang et al. 2011). Representatives of Bacteroidetes are described as important members in the maintenance of biofilm structures, e.g., participate in the initial colonization of metal surfaces, and are responsible for maintaining aerobic environments and act as predatory bacteria of other microbial species (Kirchman 2003; Dang and Lovell 2016).

In conclusion, the analysis of the Illumina sequencing results of biofilm samples maintained in isolated microcosm showed a remarkable change in bacterial community structure over 120 days. Abundance and diversity indices exhibited a distinct behavior among the samples, whereas DNA $16 \mathrm{~S}$ gene diversity analysis showed how representatives of different taxonomic levels respond to the isolated maintenance of the microcosm environment, with the change in community profile and the prevalence of few representatives. These results' guidance to understand how certain environmental factors, such as oxygen gradient, can influence the structure of a corrosive biofilm.

\section{Author's contributions}

The author read and approved the final manuscript.

Ethics approval and consent to participate

This article does not contain any studies with human participants or animals performed by the author.

\section{Competing interests}

The author declares that he has no conflict of interest.

Received: 16 August 2019 Accepted: 29 January 2020

Published online: 05 March 2020

\section{References}

Angell P, Machowski WJ, Paul PP, Wall CM, Lyle FF Jr (1997) A multiple chemostat system for consortia studies on microbially influenced corrosion. J Microbiol Methods 30:173-178

Baeckmann W, Schwenk W, Prinz W (1997) Handbook of Cathodic Corrosion Protection. Elsevier, Houston

Beech IB, Sunner J (2004) Biocorrosion: towards understanding interactions between biofilms and metals. Curr Opin Biotechnol 15:181-186

Bonifay V, Wawrik B, Sunner J, Snodgrass EC, Aydin E, Duncan KE, Callaghan AV, Oldham A, Liengen T, Beech I (2017) Metabolomic and metagenomic analysis of two crude oil production pipelines experiencing differential rates of corrosion. Front Microbiol 8:99

Boudaud N, Coton M, Coton E, Pineau S, Travert J, Amiel C (2010) Biodiversity analysis by polyphasic study of marine bacteria associated with biocorrosion phenomena. J Appl Microbiol 109:166-179
Chen S, Deng H, Liu G, Zhang D (2019a) Corrosion of Q235 carbon steel in seawater containing Mariprofundus ferrooxydans and Thalassospira sp. Front Microbiol 10:936

Chen S, Liu G, Zhang D (2019b) Corrosion behavior of Q235 carbon steel in airsaturated seawater containing Thalassospira sp. Corrosion Science 148:71-82

Dang H, Chen R, Wang L, Shao S, Dai L, Ye Y, Guo L, Huang G, Klotz MG (2011) Molecular characterization of putative biocorroding microbiota with a novel niche detection of Epsilon- and Zetaproteobacteria in Pacific Ocean coastal seawaters. Environ Microbiol 13:3059-3074

Dang H, Lovell CR (2016) Microbial surface colonization and biofilm development in marine environments. Microbiol Mol Biol Rev 80:91-138

Emerson D (2018) The role of iron-oxidizing bacteria in biocorrosion: a review. Biofouling 34:989-1000

Gohl DM, Vangay P, Garbe J, MacLean A, Hauge A, Becker A, Gould TJ, Clayton JB, Johnson TJ, Hunter R, Knights D, Beckman KB (2016) Systematic improvement of amplicon marker gene methods for increased accuracy in microbiome studies. Nat Biotechnol 34:942-949

Guo Z, Pan S, Liu T, Zhao Q, Wang Y, Guo N, Chang X, Liu T, Dong Y, Yin Y (2019) Bacillus subtilis inhibits Vibrio natriegens-induced corrosion via biomineralization in seawater. Front Microbiol 10:1111

Hamilton WA (2003) Microbially influenced corrosion as a model system for the study of metal microbe interactions: a unifying electron transfer hypothesis. Biofouling 19:65-76

Hedrich S, Schlömann M, Johnson B (2011) The iron-oxidizing Proteobacteria. Microbiology 157:1551-1564

Hsieh TC, Ma KH, Chao A (2016) iNEXT, an R package for rarefaction and extrapolation of species diversity Hill numbers. Meth Eco Evol 7:1451-1456

Kang HS, Lee SD (2009) Ponticaulis koreensis gen. nov., sp. nov., a new member of the family Hyphomonadaceae isolated from seawater. Int I Syst Evol Microbiol 59:2951-2955

Kato S (2016) Microbial extracellular electron transfer and its relevance to iron corrosion. Microb Biotechnol 9:141-148

Kirchman DL, Yu L, Cottrell MT (2003) Diversity and abundance of uncultured cytophaga-like bacteria in the Delaware estuary. Appl Environ Microbiol 69: 6587-6596

Koch GH, Brongers MPH, Thompson NG, Virmani YP, Payer JH (2002) Corrosion cost and preventive strategies in the United States. Alexandria, VA, National Technical Information Service

Koch GH, Varney J, Thompson NO, Moghissi O, Gould M, Payer JH (2016) NACE International IMPACT report

Li X, Duan J, Xiao H, Li Y, Liu H, Guan F, Zhai X (2017) Analysis of bacterial community composition of corroded steel immersed in Sanya and Xiamen seawaters in China via method of Illumina MiSeq sequencing. Front Microbiol 8:1737

Li Y, Xu D, Chena C, Li X, Jia R, Zhang D, Sand W, Wang F, Gu T (2018) Anaerobic microbiologically influenced corrosion mechanisms interpreted using bioenergetics and bioelectrochemistry: a review. J Mater Scic Technol 34:1713-1718

Little B, Lee J, Ray R (2007) A review of 'green' strategies to prevent or mitigate microbiologically influenced corrosion. Biofouling 23:87-97

Liu F, Zhang J, Zhang S, Li W, Duan J, Hou B (2012) Effect of sulphate reducing bacteria on corrosion of Al Zn In Sn sacrificial anodes in marine sediment. Mater. Corros 63:1521-1576

López MA, Zavala-Díaz de la Serna FJ, Jan-Roblero J, Romero JM, HernándezRodríguez C (2006) Phylogenetic analysis of a biofilm bacterial population in a water pipeline in the Gulf of Mexico. FEMS Microbiol Ecol 58:145-154

Lugauskas A, Prosyčevas I, Ramanauskas R, Grigucevičienè A, Selskienè A, Pakštas $V$ (2009) The influence of micromycetes on the corrosion behaviour of metals (steel, al) under conditions of the environment polluted with organic substances. Mat Sci 15:224-235

Marty F, Gueuné H, Malard E, Sánchez-Amaya JM, Sjögren L, Abbas B, Quillet L, van Loosdrecht MC, Muyzer G (2014) Identification of key factors in accelerated low water corrosion through experimental simulation of tidal conditions: influence of stimulated indigenous microbiota. Biofouling 30:281-297

McBeth JM, Emerson D (2016) In situ microbial community succession on mild steel in estuarine and marine environments: exploring the role of ironoxidizing bacteria. Front Microbiol 7:767

Melchers RE, Jeffrey RJ (2013) Accelerated low water corrosion of steel piling in harbours. Corros Eng Sci Technol 48:496-505

Miller RB 2nd, Lawson K, Sadek A, Monty CN, Senko JM (2018) Uniform and pitting corrosion of carbon steel by Shewanella oneidensis MR-1 under nitrate-reducing conditions. Appl Environ 84:pii: e00790-18 
Moura V, Ribeiro I, Moriggi P, Capão A, Salles C, Bitati S, Procópio L (2018) The influence of surface microbial diversity and succession on microbiologically influenced corrosion of steel in a simulated marine environment. Arch Microbiol 10:1447-1456

Mumford AC, Adaktylou IJ, Emerson D (2016) Peeking under the iron curtain: development of a microcosm for imaging the colonization of steel surfaces by Mariprofundus sp. strain DIS-1, an oxygen-tolerant Fe-oxidizing bacterium Appl Environ Microbiol 82:6799-6807

Park HS, Chatterjee I, Dong X, Wang SH, Sensen CW, Caffrey SM, Jack tr, Boivin j, Voordouw G (2011) Effect of sodium bisulfite injection on the microbial community composition in a brackish-water-transporting pipeline. Appl Environ Microbiol 77:6908-6017

Price SJ, Figueira RB (2017) Corrosion protection systems and fatigue corrosion in offshore wind structures: current status and future perspectives. Coatings 7:25

Procópio $L$ (2019) The role of biofilms in the corrosion of steel in marine environments. World J Microbiol Biotechnol 35:73

Rajala P, Carpén L, Vepsäläinen M, Raulio M, Sohlberg E, Bomberg M (2015) Microbially induced corrosion of carbon steel in deep groundwater environment. Front Microbiol 6:647

Ramírez GA, Hoffman CL, Lee MD, Lesniewski RA, Barco RA, Garber A Toner BM, Wheat CG, Edwards KJ, Orcutt BN (2016) Assessing marine microbial induced corrosion at Santa Catalina Island, California. Front Microbiol 7:1679

Ray RI, Lee JS, Little BJ (2010) Iron-oxidizing bacteria: a review of corrosion mechanisms in fresh water and marine environments. NACE Corros:1-19

Rondon MR, August PR, Bettermann AD, Brady SF, Grossman TH, Liles MR, Loiacono KA, Lynch BA, MacNeil IA, Minor C, Tiong CL, Gilman M, Osburne MS, Clardy J, Handelsman J, Goodman RM (2000) Cloning the soil metagenome: a strategy for accessing the genetic and functional diversity of uncultured microorganisms. Appl Environ Microbiol 66:25412547

Salerno JL, Little B, Lee J, Hamdan LJ (2018) Exposure to crude oil and chemical dispersant may impact marine microbial biofilm composition and steel corrosion. Front in Marine Sci 5:196

Salta M, Wharton JA, Blache Y, Stokes KR, Briand JF (2013) Marine biofilms on artificial surfaces: structure and dynamics. Environ Microbiol 15:2879-2893

Staniszewska A, Kunicka-Styczyńska A, Otlewska A, Gawor J, Gromadka R, Żuchniewicz K, Ziemiński K (2019) High-throughput sequencing approach in analysis of microbial communities colonizing natural gas pipelines. Microbiologyopen 6:e806

Stöhr R, Waberski A, Liesack W, Völker H, Wehmeyer U, Thomm M (2001) Hydrogenophilus hirschii sp. nov., a novel thermophilic hydrogen-oxidizing beta-proteobacterium isolated from Yellowstone National Park. Int J Syst Evol Microbiol 51:481-488

Suma MS, Basheer R, Sreelekshmy BR, Riyas AH, Bhagya TC, Sha MA, Shibli SMA (2019) Synergistic action of Bacillus subtilis, Escherichia coli and Shewanella putrefaciens along with Pseudomonas putida on inhibiting mild steel against oxygen corrosion. Appl Microbiol Biotechnol 103:5891-5905

Thompson NG, Yunocivh M, Dunmiret D (2007) Cost of corrosion and corrosion maintenance strategies. Corros Rev 25:247-261

Tiller AK, Booth GH (1962) Polarization studies of mild steel in cultures of sulphate-reducing bacteria. Part 2.Thermophilic organisms. Transact Faraday Soc 58:110-115

Tyson GW, Chapman J, Hugenholtz P, Allen EE, Ram RJ, Richardson PM, Solovyev W, Rubin EM, Rokhsar DS, Banfield JF (2004) Community structure and metabolism through reconstruction of microbial genomes from the environment. Nature 428:37-43

Videla HA, Herrera LK (2005) Microbiologically influenced corrosion: looking to the future. Int Microbiol 3:169-180

Vigneron A, Alsop EB, Chambers B, Lomans BP, Head IM, Tsesmetzis N (2016) Complementary microorganisms in highly corrosive biofilms from an offshore oil production facility. Appl Environ Microbiol 82:2545-2554

Wan H, Song D, Zhang D, Du C, Xu D, Liu Z, Ding LX (2017) Corrosion effect of Bacillus cereus on $\mathrm{X} 80$ pipeline steel in a Beijing soil environment. Bioelectrochemistry 121:18-26

Wickham H (2009) Ggplot2, Elegant Graphics for Data Analysis. NY, SpringerVerlag, New York

Xu D, Li Y, GU T (2016) Mechanistic modeling of biocorrosion caused by biofilms of sulfate reducing bacteria and acid producing bacteria. Bioelectrochemistry 110:52-58
Zheng Q, Chen C, Wang YN, Jiao N (2010) Oceanicola nitratireducens sp. nov., a marine alphaproteobacterium isolated from the South China Sea. Int I Syst Evol Microbiol 60:1655-1659

\section{Publisher's Note}

Springer Nature remains neutral with regard to jurisdictional claims in published maps and institutional affiliations.

\section{Ready to submit your research? Choose BMC and benefit from:}

- fast, convenient online submission

- thorough peer review by experienced researchers in your field

- rapid publication on acceptance

- support for research data, including large and complex data types

- gold Open Access which fosters wider collaboration and increased citations

- maximum visibility for your research: over $100 \mathrm{M}$ website views per year

At BMC, research is always in progress.

Learn more biomedcentral.com/submissions 